\title{
THE AUSTRALIAN PAEDIATRIC SURVEILLANCE UNIT
}

Kerry Chant, Research Assistant, APSU, Public Health Officer Elizabeth Elliolt, Co-ordinator, APSU, Senior Lecturer, University of Sydney. Consultant Paediatrician

The Australian Paediatric Surveillance Unit (APSU) in May 1993 began the active surveillance of eight rare paediatric conditions - AIDS, HIV infection and neonatal exposure to HIV, childhood dementia, congenital rubella, drowning/near drowning episodes, extrahepatic biliary atresia, haemorrhagic disease of the newborn, Kawasaki disease and Rett syndrome.

The APSU was formed in June 1992 and became a unit of the Australian College of Paediatrics (ACP) in May 1993. It is modelled on the British Paediatric Surveillance Unit which has been operating in the United Kingdom for eight years.

The aim of the APSU is to facilitate and improve the surveillance of rare paediatric conditions or rare complications of common paediatric conditions. Australia is particularly suited to such a scheme as its low population, large size and separate State health systems have made it difficult to obtain information on the basic epidemiology of many rare conditions.

While a rare condition affects only a small number of children, it may be associated with significant mortality and/or morbidity, result in high utilisation of health care services, and/or have significant social, emotional and financial implications for the child and family. In the case of infectious diseases there may exist the potential for wider community involvement.

Surveillance and case ascertainment, in addition to providing information on the epidemiology of rare conditions, may provide information on the aetiology, management, outcomes and health and support-related needs of the child and family. This information can be used in developing prevention strategies, identifying optimal management approaches and informing decisions about the provision of health and family support services.

The surveillance of cases experiencing a rare complication of a common condition will allow information to be gathered on a subgroup of this population. This may represent a subgroup with greater disease severity, for example, children admitted to an intensive care unit with a diagnosis of asthma. This subgroup may benefit the most from prevention and optimal medical management.

Rare condition surveillance may also be used to evaluate and review prevention strategies. The number of cases of congenital rubella, haemophillus influenzae type b infection in under five-year-olds, and drowning/near drowning episodes in under five-year-olds occurring in a specified period can be used as outcome measures to monitor the effectiveness of prevention strategies.

Rare disease surveillance will also facilitate and promote collaborative research on rare conditions and, by increasing awareness among clinicians, may prompt early diagnoses of these conditions.

A variety of methods is used to monitor the occurrence of rare conditions. These methods can be categorised as follows:

- statutory requirement to notify a condition to an organisation (e.g. NSW Infectious Diseases Surveillance System);
口 $\quad$ voluntary notification to an organisation (e.g. British Paediatric Surveillance Unit, NSW Birth Defects Registry);

death certification; and

hospital databases (e.g. NSW Inpatient Statistics Collection).

The APSU is an example of a national active case surveillance system reliant on the voluntary notification of selected conditions by participating clinicians. It is described as "active" because each month clinicians are prompted to report selected conditions by being sent a report card to complete.

All paediatricians and other clinicians working predominantly with children in Australia are sent a monthly report card. They are asked to complete the replypaid report card by indicating the number of cases of the listed surveillance conditions they have seen in the previous month or by ticking the "nothing to report" box.

The APSU maintains a database which records the clinicians' response to the monthly report card. The APSU notifies the investigator responsible for the condition on receipt of a case report. The investigator then forwards a brief questionnaire to the clinician requesting further demographic and clinical details. Identifying patient details are not requested. The first two letters of the first name and surname, date of birth and postcode are used to detect duplicate reports.

Investigators are required to provide feedback to the APSU and reporting clinicians. The investigator advises the APSU of the number of notifications meeting the case definition and the number of duplicate reports and reporting errors. The investigator also provides a brief summary of the study findings for inclusion in the APSU annual report.

The mailing list was derived from lists of paediatricians and related specialists held by the Royal Australian College of Physicians (RACP), ACP, the Health Insurance Commission and paediatric sub-specialist groups. The list is updated regularly.

Investigators complete an application form in which they outline the case definition, aims and objectives, research questions, rationale, ethical issues and funding arrangements for the study. Applications are reviewed by the Scientific Review Panel which consists of several paediatricians and a public health clinician. Applications are occasionally sent for external review by a clinician with expertise in the specialty area of the study.

In the event of an epidemiological emergency the APSU can promptly add a new condition to the card and institute telephone reporting if necessary. This situation may arise in the case of a newly described condition, where there are new concerns about a side effect from a vaccine or other treatment, or where a change in public health policy is to be adopted and the effect of this change needs to be monitored.

Investigators are required to obtain ethics approval from their institution before a condition can be listed on the card.

The response rate for the first five months of the APSU's operation has been about 85 per cent. While we aim for a response rate of more than 90 per cent we are pleased with the progress and appreciate the cooperation of clinicians.

The Australian Paediatric Surveillance Unit can be contacted at The Children's Hospital, PO Box 34, Camperdown NSW 2050. 